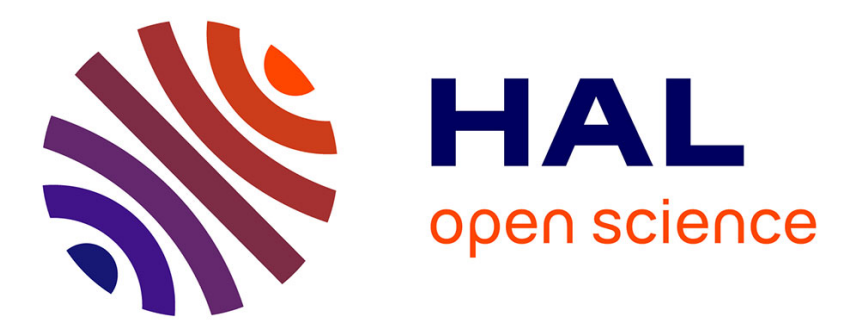

\title{
Corporate acquisistion process: is there an optimal cash-equity payment mix?
}

\author{
Hubert de La Bruslerie
}

\section{To cite this version:}

Hubert de La Bruslerie. Corporate acquisistion process: is there an optimal cash-equity payment mix?. International Review of Law and Economics, 2012, 32, pp.83-94. 10.1016/j.irle.2011.07.003 . halshs-00636349

\section{HAL Id: halshs-00636349 \\ https://shs.hal.science/halshs-00636349}

Submitted on 27 Oct 2011

HAL is a multi-disciplinary open access archive for the deposit and dissemination of scientific research documents, whether they are published or not. The documents may come from teaching and research institutions in France or abroad, or from public or private research centers.
L'archive ouverte pluridisciplinaire HAL, est destinée au dépôt et à la diffusion de documents scientifiques de niveau recherche, publiés ou non, émanant des établissements d'enseignement et de recherche français ou étrangers, des laboratoires publics ou privés. 


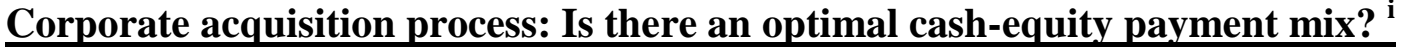

\author{
Forthcoming in International Review of Law and Economics
}

doi:10.1016/j.irle.2011.07.003

\author{
Hubert de La Bruslerie \\ Professor of Finance \\ DRM Finance-UMR CNRS 7088 \\ Université Paris Dauphine \\ Place du Mal de Lattre 75116 Paris - France \\ (33) 144054405 hlb@dauphine.fr
}

\begin{abstract}
:
This paper examines the combination of cash and share payments proposed in the corporate acquisition process. Particularly, it analyzes the conditions of an optimal mixed payment in the context of an asymmetry of information. Using a model, we highlight that setting the conditions of payment is an endogenous part of a takeover agreement between the acquirer and the target. Our contribution is to show how, in the acquisition process, the setting of the cash percentage is a key element for conveying private information on the gains of synergy and the gains that result from the transaction. In our model, we internalize asymmetries of information and possible exaggeration biases. Both will influence the joint setting of a mixed payment scheme.
\end{abstract}

\section{JEL: G3/G34}

Keywords: mergers and acquisitions, information asymmetry, means of payment, contractual approach, synergy gains

\footnotetext{
${ }^{\mathrm{i}}$ This paper was presented at research seminars at HEC Geneva and the University of Fribourg, at the 2006 AFFI meeting in Poitiers, the 2007 EFMA Symposium on corporate governance in Milano, and the 2007 CIG International Conference on Corporate Governance in Geneva. I thank F. Dumont, E. De Bodt, M. Hoesli, D. Isakov, M. Levasseur and two anonymous referees for their remarks. This research benefited from the support of the "Fédération Bancaire Française" Chair in Corporate Finance.
} 


\section{Corporate acquisition process: Is there an optimal cash/equity payment mix?}

\section{Introduction}

Merger and acquisition transactions may appear similar regardless of whether the payment is made by cash or by issuing new shares. However, if these means of payment were equivalent, a mixed payment with both cash and shares would also be redundant. In fact, many massive takeover bids with mixed payment schemes have recently occurred. In a sample of 1,361 European acquisitions, Martynova and Renneboog (2009) evidenced that mixed cash-equity payments represent $19 \%$ of the number of transactions, more than full equity payments (18.2\%). On the theoretical side, Eckbo et al. (1990) signal that mixed offers are considered an "enigma." Recalling that most mergers are non-hostile, the question of the optimal mode of payment arises independently of the existence of a competition between bidders.

The endogenous nature of mixed cash-equity payments has not been extensively addressed in the literature, at least from a contractual approach. An information asymmetry problem is at the heart of the optimal design of cash-equity payments in such a context. The purpose of the paper is to design the optimal mixed-payment scheme in a framework of double asymmetry of information and to examine how the acquisition process may lead to a joint agreement in determining the optimal ratio for cash-share payments. The cash percentage variable is a full part of the agreement and has to be set optimally, considering the information level of both parties. Paying with stocks will allow for risk sharing. The risk is not only an economic risk of value but also an information risk due to the discrepancies between the information levels of each party and to the possible exaggeration from one party to the other. The acquirer has imperfect information about the target firm and may fear that information delivered by the seller is possibly biased. Conversely, the seller does not know what the gains of synergy will be when the acquisition is complete.

Since Hansen (1987) and Eckbo et al. (1990), theoretical analysis of the design of mixed payment in mergers and acquisitions (M\&As) has been limited. We add to this literature by following a contractual approach. Using a one-period model, this paper contributes to the analysis of the joint setting of cash-equity payment schemes in the acquisition process. We outline the trade-off between the percentage paid in cash and the percentage of the economic 
gain of the whole acquisition captured by the target's shareholders. The cash percentage is also linked to the economic context of the acquisition through the correlation coefficient between the expected gains on the target's assets and the acquirer's assets. Economic diversification motives will impact the scheme of payment. Thus, the payment mix may retroactively influence the offer price. We show how the cash-percentage setting is a key element of private information sharing regarding the gains of synergy and the gains resulting from the transaction. In our model, we internalize asymmetries of information and possible exaggeration biases from both sides. These factors will influence the joint setting of a mixed payment scheme. The role of a company's communication policy is identified in the process of the transaction. A selfbalanced process that involves the idea of trustworthiness is identified. It appears that the final takeover price should be sensitive to the design of the payment scheme and that disclosing pieces of private information is a necessity during the negotiation process. We derive testable propositions from the model.

The first Section will review the prior literature. The second Section will set the model and solve the optimal payment structure in a context of asymmetrical information between the buyer and the seller. The third Section introduces the role of communication policies and analyzes the process of negotiation between the buyer and the target shareholders.

\section{$\underline{1 \text { - Literature Review }}$}

The literature on means of payment developed both on empirical and theoretical grounds. The use of mixed payment schemes was proposed as a third means, between full-share and full-cash payments. In the empirical literature, mixed payments are not explained but rather observed. Analytical attention was first given to the alternate choice between cash or share payments. The theoretical literature explaining mixed payments is essentially based on the asymmetry of information.

\subsection{Empirical analysis}

The empirical literature on mixed cash-equity payments is relatively recent. On factual grounds, mixed payment schemes have become increasingly important in mergers and acquisitions, particularly when considering offers for large firms. Goergen and Renneboog (2004) analyzed public takeover bids in Europe during the 1990s. Examining a sample of 156 offers, 93 were pure cash, 37 were pure shares, and 18 were mixed payments. Faccio and Masulis (2005) 
considered a larger sample of 3,667 mergers or acquisitions of European firms at the end of the 1990s. Mixed payment bids account for only $11.3 \%$ of these M\&As. However, the average size of a mixed-payment takeover bid was five times (1.1 billion USD) greater than the size of a standard pure cash offer (209 million USD). Mixed payment schemes represent a far greater proportion of transactions, as the value of the transactions rises. However, this discrepancy is largely explained by cross-border transactions, where many small deals are paid in cash. Cash payments seem to be more frequent with relatively small targets, with a total of $80.2 \%$ of the number of transactions completed entirely in cash. In recent years, the number of mixedpayment takeovers has been increasing. Martynova and Renneboog (2006) considered 1,721 European takeovers between 1993 and 2001 and discovered that 54\% were all-cash, 25\% were mixed, and 20\% were all-equity transactions. Ben-Amar and Andre (2007) examined 293 Canadian mergers and acquisitions over the period of 1998-2002. The average composition was $58 \%$ cash-only, $19 \%$ stocks-only and $22 \%$ mixed payments. However, the latter represented $32.3 \%$ of the total value of the transactions, indicating that mixed-payment takeovers occur particularly in the highest valued transactions. For mixed-payment takeovers, the average percentage of cash was $49 \%$, but the standard deviation was $50 \%$, corresponding to huge differences between payment schemes.

\subsection{Influence of the context of the transaction}

Cash payments typically represent a larger share of cross-border acquisitions. An information asymmetry problem develops, as the value of assets of a foreign company is more difficult to assess. The greater the distance between firms, the higher the percentage of payments in cash (Chevalier and Redor, 2010). A dividend-catering hypothesis has been proposed by Zhang (2009). This hypothesis explains the percentage of cash payments in acquisitions. Conversely, the tax system favors equity payments. Share payments will entail deferred tax payments (see the survey by Chevalier and Redor, 2007). The competitive nature of the takeover has been identified in the literature as a strong argument for cash payments (Fishman, 1989; Berkovitch and Narayanan, 1990). Cornu and Isakov (2000) developed a model in the context of a competitive offer between two acquiring firms. Pure cash offers are dissuasive because they reveal a buyer with a strong will to acquire the target firm. Yet, the majority of mergers and acquisitions are non-hostile. The characteristics of the payment scheme have to be analyzed in the context of the known success of the takeover. 
The analytical literature that explains mixed-payment schemes in M\&As follows the standard strands of corporate financing theory or focuses on signaling equilibrium and the asymmetry of information.

\subsection{Corporate financing theory, governance and control}

The question of partial payment in cash may express the existence of financial constraints. If the financial leverage is binding, cash financing is limited by the possibility of raising debt (Myers and Majluf, 1984). Payments of acquisitions with cash, whether full-cash or mixed-cash payments, need to be financed. The acquirer may issue and sell new equity stocks, issue debt or use the firm's cash holdings. Martynova and Renneboog (2009) empirically analyzed the financing decisions behind the choices of the means of payment in M\&A transactions. They found that the financing choices are not systematically linked with the means of the payment choices.

Corporate governance may also help to analyze the means of payment in public or private takeover offers (Amihud et al., 1990, Martin, 1996). Faccio and Masulis (2005) explain mixed payments in takeovers both by the structure of the control and the debt level of the acquiring firms. Accordingly, payment in cash, which is considered equivalent to issuing debt, does not modify the control of a dominant shareholder of the acquiring firm. Conversely, payment by shares can easily modify the structure of ownership and control, particularly in European firms, where some shareholders are dominant. Faccio and Masulis' test on European mergers and acquisitions supports the idea of a preference for a cash payment when there is a large shareholder owning $20 \%$ to $60 \%$ of the capital of the buyer. Managers also prefer cash financing when they own a significant portion of the capital directly or indirectly through stock options (Stulz, 1988). Buying a target of which ownership is concentrated may unbalance the controlling ownership of the buyer because a new blockholder joins the control game (Chang and Mais, 2000).

\subsection{Signaling, asymmetry of information and risk sharing explanation}

The means of payment can be viewed as a signal to the market. In a certainty context, a takeover will become impossible if the target's shareholders know their company's true value because they will ask for a price that is at least equivalent to that value (Grossman et Hart, 1980). Most analyses assume a situation in which the acquirer has better private information on the overall outcome of the acquisition than the target. Shareholders of the target firm have 
lower information on its future value. The means of payment disclose a signal regarding the future economic perspectives of the two merged firms. A $100 \%$ cash offer is a good signal; the buyer has sufficient reliable information about the target. An empirical study by Megginson et al. (2004) on the long-term performance resulting from mergers confirms that a cash payment is a reliable signal of the future creation of value. Long-term underperformance of purely stockfinanced deals, consistent with the results of Megginson et al., has been shown by Loughran et al. (1997), André et al. (2004) and Antoniou and Zhao (2004). Other authors (Gosh, 2001; Linn et al., 2001) have found that cash acquisitions may also be empirically associated with better operating performance.

The market-signaling role of the means of payment was also studied within several event-study works (Travlos, 1987; Amihud, Lev and Travlos, 1990; Bellamy and Lewin, 1992, Martin 1996, Houston and Ryngaert, 1997). The acceptance of a payment with shares by the target's shareholders signals favorable perspectives of future profits. Chang (1998) outlines the idea that private takeovers using share payments are linked to important and positive abnormal returns in the United States. Similar studies were proposed by Fuller et al. (2002) in the United States and by Da Silva Rosa, Limmack and Woodliff (2003) in Australia. Goergen and Renneboog (2004) also provide evidence for the role of the means of payment with a sample of public European offers. However, these studies were mostly based on $100 \%$ cash or share payments.

Previous works have not explicitly considered the very specific case of the payment-scheme design in the process of a takeover with double information asymmetry between an acquiring firm and a target company. Hansen (1987) was the first to mention that each manager/shareholder has private information on his own value and has incomplete information on the nature of the assets he receives. The bidding firm buys assets of an uncertain value and may want to share the valuation risk by paying with equity based on the newly merged group. The target's shareholders will receive shares on a new economic project based on forecasted profits and synergies. They may also insure themselves by receiving cash and avoiding shares. Hansen (1987) introduced the idea of a "double lemons effect" and risk-sharing behaviors. The fraction of equity capital the bidder wants to receive reveals private information about the buyer's future value and expected profits. If the choice of the means of payment discloses private signals to other parties, it will in return also influence the process of negotiation. Hansen's model explains the probability of paying in cash or in shares but does not focus on mixed-payment schemes. Eckbo, Giammarino and Heinkel (1990) refer explicitly to an optimal 
mixed cash-shares payment and were the first to highlight that weighing between these two means of payment will reveal to other parties the respective quality of competitive buyers. Recent contributions are empirical papers. Chang (1998) expanded on the idea that an exchange of information can help solve the problem of double information asymmetry. He introduced a prior holding in the target's capital ("toehold") as a means to reduce the buyer's asymmetry of information. In such a situation, the buyer has better inside knowledge of the target, especially if he holds a large portion of the capital. Heron and Lie (2002) find no evidence that the method of payment conveys information about the acquirer's future operating performance. Cheng et al. (2008) used a sample of US firms to compare the asymmetry of information, bid premiums and the means of payment. They showed that the means of payment and bid premiums are interdependent, with means of payment heavily conditioning the price paid in the deal for a given asymmetry of information between the two parties. This suggests that the two terms are linked from a contract-design perspective.

\section{2-Optimal payment mix and the role of information asymmetries}

A model of agreement setting between acquiring and target firms allows for obtaining more insight into the payment-mix decision. M\&As are contracts to sell the assets of the target firm to a buyer with the goal of creating a merged entity. The double information-asymmetry problem is at the heart of the optimal design of cash-equity payments in a contractual approach.

\subsection{Assumption and setting of the model}

The question remains regarding how to set a payment scheme in the situation of double information asymmetry between risk-averse buyers and sellers. This has not been extensively analyzed in the literature, except in the process of a takeover with several competitors. Here, we assume that the success of the takeover is certain at a generally agreed-upon price. Nevertheless, the means of payment are to be set. A payment with shares is a guarantee against a possible valuation mistake of the target. It allows the splitting of, first, the future gains ensuing from the acquisition and, second, the risks between parties. The buyer can imagine other ways to guarantee his purchased value of the target firm; the buyer can be asked to guarantee a limited value on the liabilities, which means that in the case of hidden or possible losses, the seller will reimburse all or a portion of the losses. The acquirer can also pay a transaction price indexed on future activity or profit figures. Another solution is to make the seller share in the risk and uncertainties of the value of the acquired firm and future gains by 
transforming him into a shareholder of the newly merged firm. A partial payment in shares is a self-insured policy when facing information asymmetry with the target firm. The target shareholders paid with shares will receive a part of the uncertain future profits or losses ensuing from the acquisition. However, a payment with shares dilutes the equity of the current shareholders of the acquirer.

Hereafter, we will only consider the dilution of the capital of the acquirer's current shareholders and will not refer to agency conflicts within the firm or to financial constraints. Acquisition gains and synergies are uncertain, and the shareholders of both the target and acquiring firms are risk averse. Because of dilution, future profits and gains will be shared with the newly associated shareholders. A full-cash payment will entail two certainties: a fixed and risk-free price for the sellers and a total appropriation by the acquirer of the uncertain expected profits.

The model will take into account the case of double asymmetry of information and the necessary equilibrium implicit in agreement on the offer. The target's shareholders are not passive. They also have a preferred scheme of payment, even if it is not formally made explicit at the beginning of the process. The mix-of-payment issue can appear in the process, for instance, through counter-offers. The weighing of the means of payment will reveal private information.

The offer price has to be taken into account in the analysis. The incumbent controlling blockholder agreement to sell is known. If the choice of the means of payment has value, it interacts with the final price. Even if the takeover is certain, the balance between cash and shares may influence the sharing of the synergy gains. In such a situation, the takeover price agreed upon by the buyers and the sellers will be retroactively influenced by the means of payment. A non-hostile offer is considered here. In the purely contract-setting process, we suppose that the acquirer has no financial constraints or limits to finding cash (or debt) or to issuing new shares. Financial constraints lead to a "corner solution" for full-cash (full-debt) financing. Here, we want to explain mixed payment schemes within the 0 to $100 \%$ cash payment range without referring to the financing constraints that ensue, for instance, from the leverage ratio of the bidder. In the model, we will privilege the feature of double information asymmetry in a contractual approach. It does not preclude that financial limits may also exist in a given mix-payment setting, but we want to show that the mixed-payment design may appear without assuming financing limitations. This is in line with Martynova and Renneboog's 
empirical analysis of the financing decisions between equity and cash (or debt) in M\&As. They find that neither the financial leverage nor the collateral are significant variables (see table $4, \mathrm{p}$. 307). The collateral is used to characterize the debt capacity of the initiator. The financial constraints, or the limits on receiving cash, do not seem effective to explain the choice of cash payment, but the relative value of the two firms is. On the other end of the "corner solutions," equity-only payments are linked with large deals. The average offer paid fully in stocks is 3.5 billion USD in Faccio and Masulis' (2005) sample. It is 17 times the average size of a full-cash transaction. This can be explained by the pecking order theory or by the overvaluation of the share, which allows the initiator to time the market and issue new equity. It can also be explained by the risk-sharing motive. The share-price appreciation variable is not systematically significant in the empirical test in either the Faccio and Masulis (2005) or Martynova and Renneboog (2009) papers. The absolute size of the initiator does not seem to be empirically connected with a means of payment (according to Martynova and Renneboog, 2009). However, we observed that the relative size is significant in explaining partial or total payment in shares. Thus, we are left with the idea that the relative size of a transaction compared to the acquirer's possibilities becomes a problem of financial leverage because the limitation takes a proportional form.

This appears, in our model and others, through the relative size variable. The acquirer sets his problem by considering his own size as a given characteristic for any deal. From that benchmark, the relative size variable is sufficient to appreciate the size of the target in his economic calculus. The size of the target is a relative problem for assessing the asymmetry of information (Hansen 1987) or for assessing the limits of financial debt capacity. The absolute size of the target does not appear as a control variable in the empirical literature on the determinants of the mix of payment (Ben Amar and André, Faccio and Masulis, Martynova and Renneboog). We model payment schemes as independent from corner solutions, which lead to cash-only or shares-only payments. Financial limits or share overvaluations are supposed to be non-binding conditions in the mixed-payment setting, as the empirical literature on European M\&As may suggest.

The transaction value of the target firm is first set as an estimate. The transaction is agreed upon in principle, but the means of payment have yet to be determined. The variables are the following: 
$\tilde{A}$ : uncertain value of the assets of the target firm A after the acquisition $A_{D}$ : acquisition price of the target firm ( $D$ for "deal")

$A_{0}$ : value of the target firm before the announcement

$\tilde{S}$ : uncertain future value of the acquiring firm after the takeover

$S_{0}$ : value of the acquiring firm set at transaction

$k$ : percentage of the offer paid with cash; total cash payment is $k \cdot A_{D}$

$\alpha$ : ratio of value between the two firms set for the acquisition, $\alpha . S_{0}=A_{D}$

$c$ : fraction of the acquisition and synergy gains captured by the sellers

$\widetilde{\varepsilon}_{A}$ : total gains (or losses) of acquisition by the buyer regarding his assets. A tilde indicates a random variable; the symbol without a tilde is the expected value of the gains.

$\sigma_{A}$ : standard deviation of the acquisition gains regarding the $\mathrm{A}$ assets

$\widetilde{\varepsilon}_{S}$ : economic acquisition gains of the buyer regarding his assets and synergy gains after merging; without the tilde it is the expected value of the gains.

$\sigma_{s}$ s standard deviation of the acquisition and synergy gains regarding the acquirer S's assets

As mentioned above, capital constraints on the acquirer's side, which may limit the borrowing capacity to obtain cash, are not introduced in the model. Additionally, tax considerations are not taken into account. In such a situation, the absolute size of the target company will not influence the mix of payments through a possible limit to indebtedness ${ }^{2}$. The two parties are the target's shareholders and the acquirer's shareholders. Agency conflicts with managers are not introduced. Neither entrenched managers (who eventually have preferences on the means of payment) nor the existence of private benefits resulting from controlling shareholder ownership are considered. The purpose is to define an implicit contract process between the shareholders of the target and the acquirer, with each one considered a whole. ${ }^{3}$ The seller and buyer have agreed on the principle of an acquisition, and the price is settled; however, some terms of the deal still have to be negotiated. The price is paid partly in cash and partly in shares of the acquiring firm:

$$
A_{D}=k A_{D}+(1-k) \alpha S_{0} .
$$

The future value of the target firm's assets has an expected value $A_{0}+\varepsilon_{A}$ and a standard deviation $\sigma_{A}$. We consider the certainty-equivalent wealth of risk-averse investors with a riskaversion coefficient $\mu$. The buyers and sellers (i.e., the shareholders of, respectively, the acquirer and the target firms) have identical risk aversion. ${ }^{4}$ Both feel uncertain about the value of the assets of the other party. 
The value of the acquirer after the takeover will depend on the random value of the target's assets, $\tilde{A}$. Those assets have an uncertain economic value from the acquirer's point of view. Gains or losses $\left(\varepsilon_{A}\right)$ are possible, about which the target's shareholders may have better information. These assets are merged with $\mathrm{S}$ after the acquisition. Conversely, specific uncertainty is introduced for the target's shareholders who receive shares from the acquirer S. At the $\mathrm{S}$ level, the economic future profit for the initiator, which results from the acquisition of A, is $\varepsilon_{S}$. This variable covers possible economies of scale and gains of synergy, which are unknown by the target's shareholders. We presume that $\varepsilon_{S}$ is positive. The expected total acquisition gain resulting from the takeover is $\left(\varepsilon_{A}+\varepsilon_{S}\right)$, which is the sum of the gain extracted from $\mathrm{A}$ and the gain created by $\mathrm{S}$ in the management of the newly merged firms. These two random variables are not independent. When the acquisition leads to a diversified group, the two processes of value creation are poorly correlated. When merging occurs in the same economic activity or seeks economies of scale, the correlation $\rho$ between $\widetilde{\varepsilon}_{A}$ and $\widetilde{\varepsilon}_{S}$ may be important and positive. The expected gross economic value of the merged firm after acquisition is $\left(S_{0}+A_{0}+\varepsilon_{A}+\varepsilon_{S}\right)$. The global value of the consolidated firm has to take into account the negative cash flow resulting from the cash payment:

$$
\left(S_{0}+A_{0}+\varepsilon_{A}+\varepsilon_{S}\right)-k A_{D}
$$

The transaction price, $A_{D}$, includes a sharing of the future economic gain, as expected by the buyer and the seller, regardless of whether it comes from A or S.

The target firm may deliver biased information about the future acquisition gain resulting from his assets (or similarly, the buyer receives noisy information about the acquisition gain). This bias is represented by the variable $i_{A}$. If its average value is positive, the overestimation corresponds to manipulated and exaggerated information or to the hiding of losses. A situation with a negative $i_{A}$ is also possible and would correspond to a buyer who underestimates the profitability of A's assets (or exaggerates future losses). The selling firm knows the exact distribution of the acquisition gain on his assets. The information is better on this point. The seller uses $\widetilde{\varepsilon}_{A}$ in his calculus. Meanwhile, the buyer considers the following: $\widetilde{\varepsilon}_{A, b}=\widetilde{\varepsilon}_{A}+\tilde{i}_{A}$. The noise term has an expected value $i_{A}$ and a standard deviation $\sigma_{i A}$. The buyer knows that he is exposed to a specific information risk regarding the seller's assets. From his point of view, the two information and economic risks are independent and cumulative; thus, $\sigma_{A, b}^{2}=\sigma_{A}^{2}+\sigma_{i A}^{2} 5$. The acquirer, who is not completely naïve, perceives the information bias. This bias is given an 
expected value and a standard deviation. The latter measures the quality of information as perceived by the buyer. We introduce a trustworthiness mechanism in the process of information being delivered by one party to the other. We will suppose that $d i_{A} / d \sigma_{i A}$ is positive. Moreover, the more the buyer exaggerates optimistic information, the less this information appears to be high quality. This assumption will help in developing self-limitation mechanisms in the process of acquisition for both parties.

The value of the acquiring company is also uncertain. The buyer's assets will generate future acquisition gains, which will benefit both the previous shareholders and the new shareholders, through a share payment. The combination of the buyer's and the seller's assets through acquisition will create synergies or crossed effects of which estimation is uncertain, but the manager (and then the current shareholders) of the buyer has better information. The random variable $\widetilde{\varepsilon}_{S}$ represents the expected acquisition and synergy gains specific to the buyer. The possibility of the buyer influencing the seller's shareholders by manipulating information on the future perspectives of economic gains resulting from the acquisition is acknowledged. For instance, a public notice of large synergy gains may increase the perceived value of the buying firm and the proportion of payment with shares. ${ }^{6}$ The seller has lower information on future synergy gains and perceives them with an uncertain bias set in absolute terms: $\widetilde{\varepsilon}_{S, s}=\widetilde{\varepsilon}_{S}+\tilde{i}_{S}$.

The process of transaction develops in a non-homogeneous information set and leads to a double calculation. The acquisition occurs at the transaction price $A_{D}=k A_{D}+(1-k) \alpha S_{0}$. The exchange ratio between seller A's assets and buyer S's assets is viewed differently according to each party's perspective because each one has his own perspective on profits (and, consequently, his view of the captured part of the gains):

$$
\begin{aligned}
& A_{D}=A_{0}+c_{b}\left(\varepsilon_{A, b}+\varepsilon_{S}\right)=A_{0}+c_{b}\left(\varepsilon_{A}+\varepsilon_{S}+i_{A}\right) \\
& A_{D}=A_{0}+c_{s}\left(\varepsilon_{A}+\varepsilon_{S, S}\right)=A_{0}+c_{S}\left(\varepsilon_{A}+\varepsilon_{S}+i_{S}\right)
\end{aligned}
$$

The exchange ratio $\alpha$ is always $A_{D} / S_{0}$, but the transaction price is affected by the average value of the information bias for each party. The two parameters $c_{b}$ and $c_{s}$ are ex ante part of the gain captured by the target, as perceived by the buyer's and the seller's shareholders, respectively.

\subsection{Situation of the acquirer's shareholders}

For the target's shareholders, the minimum incentive condition to participate in the game and to accept the deal is $A_{D}>A_{0}$, which means a positive value of $c_{s}$ (if $\varepsilon_{A}+\varepsilon_{S}+i_{S}>0$ ). At least, the 
sellers want to capture a part of the acquisition profit/synergy gains. The term $\left(1-c_{b}\right) \cdot\left(\varepsilon_{A}+\varepsilon_{S}+\right.$ $i_{A i}$ ) represents the remaining part of the acquisition gains on the assets of $\mathrm{A}$, which benefits the buyer. A situation where $c_{b}<1$ if $\left(\varepsilon_{A}+\varepsilon_{S}+i_{A}\right)<0$ may occur and would correspond to the selling of A's assets with significant and probable future losses; the seller would agree to bear a part of the loss.

Following the issuance of new stocks to pay the target firm's shareholders, the equity capital becomes (see relation (1)) $S_{0}[1+(1-k) \alpha]$. The acquirer's shareholders are diluted in the new equity capital structure of the firm. Their share in the equity decreases by a coefficient of $1 /[1+(1-k) \alpha]$. New shareholders from the target firm will own a fraction $(1-k) \alpha /[1+(1-k) \alpha]$ of the capital of the merged group. Their participation in the new ownership structure is (via the transaction exchange ratio of values, $\alpha$ ) increasing by $A_{D}$, the transaction price of the target (and also by the captured fraction of acquisition gains). ${ }^{7}$ The expected profit for the buyer (i.e., the acquiring firm's current shareholders) comes from the gross acquisition profit to be shared between all (prior and new) shareholders. This gross profit equals the increase of the net equity value of the firm. Considering the economic value after merging (see equation (2)), we obtain the following:

$$
\tilde{\pi}_{b}=\left[\left(S_{0}+A_{0}+\widetilde{\varepsilon}_{A}+\widetilde{\varepsilon}_{S}+\tilde{i}_{A}\right)-k A_{D}\right]-S_{0}[1+(1-k) \alpha]
$$

Replacing the previous equation with (1) and (3), we check that the buyer's gross profit is equivalent to the non-captured portion of the acquisition gains:

$$
\tilde{\pi}_{b}=(1-c)\left(\widetilde{\varepsilon}_{A}+\widetilde{\varepsilon}_{S}+\tilde{i}_{A}\right)
$$

The acquisition profit of the acquiring firm and the synergy gains go to its shareholders. Among them are the target's current shareholders, who are paid with the issuance of new shares. We must examine the net wealth of the prior takeover shareholders because they have ex ante decided to launch the operation. The buyer's current shareholders' expected profit weighted by their part in the new equity capital is

$$
\pi_{b}=\frac{\left(1-c_{b}\right)\left(\varepsilon_{A, b}+\varepsilon_{S}+i_{A}\right)}{1+(1-k) \cdot \alpha}
$$

The net profit is the uncaptured portion of the acquisition gains corrected by a dilution factor. The expected profit, $\left(\varepsilon_{A}+\varepsilon_{S}+i_{A}\right)$, should at least be positive; otherwise, the buyer will not bid. The derivation of the optimal payment in cash gives (see Annex 1) the following:

$$
k_{b}^{*}=1+\frac{S_{0}}{A_{0}+c_{b}\left(\varepsilon_{A}+\varepsilon_{S}+i_{A}\right)}\left(1-\frac{\left(1-c_{b}\right) \mu\left(\sigma_{A, b}^{2}+\sigma_{S}^{2}+2 \rho \sigma_{A, b} \sigma_{S}\right)}{\left(\varepsilon_{A}+\varepsilon_{S}+i_{A}\right)}\right)
$$


The greater the risk in the acquisition gain, the lower the proportion of the payment in cash $\left(d k / d \sigma_{A, b}<0\right)$. This corresponds to protective behavior from the buyer; as a result, the proportion paid in shares is positively linked to the aversion coefficient. The coefficient $\rho$ measures the correlation between the two drivers $\widetilde{\varepsilon}_{A}$ and $\widetilde{\varepsilon}_{S}$ of the value created though the acquisition and indicates the possible gains resulting from an acquisition with a possible decrease in economic risk at the merged firm level, which is equivalent to a creation of value. The correlation allows for the definition of the economic goal of the acquisition, that is, economic diversification (negative $\rho$ coefficient) or, on the contrary, vertical or horizontal integration (positive and high $\rho$ ). From (5), we observe that $d k_{b} * / d \rho$ is negative. For correlated activities between the target and acquiring firms (i.e., a positive $\rho$ ), the optimal cash-payment percentage is lower for the bidder. This means that the acquirer needs to insure itself more against uncertainty by increasing the share portion of the payment. Conversely, if the correlation is zero or negative, the economic diversification lowers the global economic risk of the merged firms and allows for a higher payment in cash.

The two information noises, $i_{A}$ and $\varepsilon_{A}$, are presumed to be independent. This assumption means that at the target-firm level, the size of the information bias is not linked to the existence of gains (or losses). This is questionable because, for instance, we can imagine that a seller can be pushed to issue optimistically exaggerated information insofar as he fears possible losses after the acquisition. We then obtain

$$
k_{b}^{*}=1+\frac{1}{\alpha}-\frac{\left(1-c_{b}\right) \mu\left(\sigma_{A}^{2}+\sigma_{S}^{2}+\sigma_{i A}^{2}+2 \rho\left(\sigma_{A}^{2}+\sigma_{i A}^{2}\right)^{1 / 2} \sigma_{S}\right)}{\alpha\left(\varepsilon_{A}+\varepsilon_{S}+i_{A}\right)}
$$

The $k_{b} *$ value is upwardly limited by 1 . We draw the following condition to give a negative or null value to the last two terms of the right side of equation (6):

$$
\left(\varepsilon_{A}+\varepsilon_{S}+i_{A}\right) \leq\left(1-c_{b}\right) \mu\left(\sigma_{A}^{2}+\sigma_{S}^{2}+\sigma_{i A}^{2}+2 \rho\left(\sigma_{A}^{2}+\sigma_{i A}^{2}\right)^{1 / 2} \sigma_{S}\right)
$$

Condition (C1) means that significant risk in the value of the future acquisition gains combined with positive risk aversion leads to mixed schemes of payment $(k<1)$, corresponding to insurance motivation by the buyer. Conversely, when the risk is low or the expected profit is high, the optimal payment is a pure cash payment $(k=1)$. The condition $(\mathrm{C} 1)$ reveals in the buyer a concern about the mix of the means of payment. If that condition is not satisfied, the pure cash payment is optimal and is the only one to be considered. This explains why full-cash, full-shares and mixed schemes of payment are empirically observed. Therefore, the limit condition $(\mathrm{C} 1)$ is presumably verified. Figure 1 shows that the choice of the mix of payment is 
bordered by the shares-only/full-insurance and cash-only/no-insurance corner solutions. The mix-of-payment choice is set according to the expected profit for the acquirer. The space for hybrid payment depends on $\alpha$. The larger $\alpha$ is (i.e., the larger the target size relative to the acquired), the more room there will be for a mixed payment.

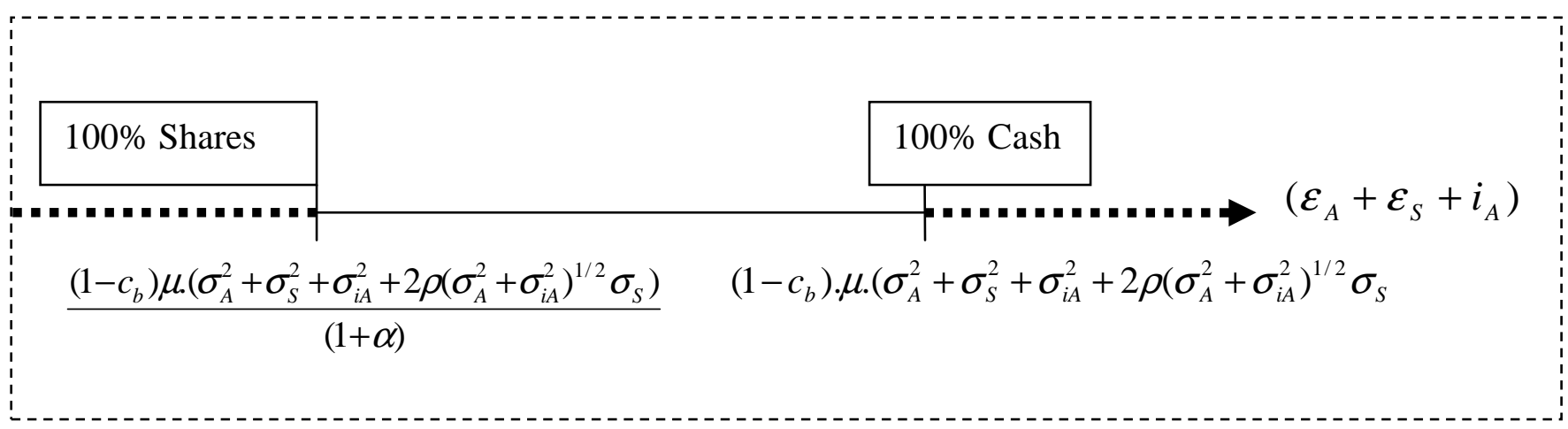

Figure 1 Choice of the means of payment according to the expected profit for the acquirer

We have to question whether the optimal cash payment is a systematically increasing function of the expected profit by the buyer on the assets A of the target firm. ${ }^{8}$ The effect of the acquisition gain is measured by the derivative of $k^{*}$ with regard to the global gain, as perceived by the buyer $\varepsilon_{A}+\varepsilon_{S}+i_{A}$ :

$$
\frac{d k_{b} *}{d\left(\varepsilon_{A}+\varepsilon_{S}+i_{A}\right)}=\frac{\left(1-c_{b}\right) \mu\left(\sigma_{A, b}^{2}+\sigma_{S}^{2}+2 \rho \sigma_{A, b} \sigma_{S}\right)}{\alpha \cdot\left(\varepsilon_{A}+\varepsilon_{S}+i_{A}\right)^{2}}>0
$$

Therefore, $d k_{b} / d\left(\varepsilon_{A}+\varepsilon_{S}+i_{A}\right)$ is positive; the proportion of the cash payment increases with the acquisition gain. The buyer pays more in cash if the prospects of value creation are high; this corresponds to a lower need to be insured through sharing the risk with the seller. Reasons different from those evoked by Eckbo et al. (1990) draw the same result of increasing cash payments.

The derivative of $k_{b}$, with regard to the information bias issued by the seller, is obtained from (6), reminding us that the exchange ratio $\alpha$ will also depend on $i_{A}$ for the buyer. From the latter's perspective, the transaction price is $A_{D}=A_{0}+S_{0}+c_{b}\left(\varepsilon_{A}+\varepsilon_{S}+i_{A}\right)$, with the following:

$$
\frac{d k_{b}^{*}}{d i_{A}}=\operatorname{sgn}\left[-c i_{A}^{2}+(1-c) \mu\left(\sigma_{A}^{2}+\sigma_{S}^{2}+\sigma_{i A}^{2}+2 \rho\left(\sigma_{A}^{2}+\sigma_{i A}^{2}\right)^{1 / 2} \sigma_{S}\right)\left(A_{0}+2 c . i_{A}\right)\right]
$$

Introducing condition (C1) means that a lower value of (8) is always positive; thus, we obtain a positive $d k_{b} * / d i_{A}$. Using (6), we verify that $d k_{b} * / d \sigma_{i A}{ }^{2}$ is negative. An optimistic bias from the seller $\left(i_{A}>0\right)$ means a higher proportion of cash. Here, the bias $i_{A}$ is not observed by the buyer 
but instead is issued by the seller and incorporated into the buyer's forecasts. Thus, a seller who wants, for instance, a higher proportion of cash can manipulate the buyer. Such behavior cannot be endless. It can be presumed that an overly high bias (and an overly high expected value of the future gain) as perceived by the buyer will cause him to become increasingly doubtful. The information of the target is then perceived as fuzzy and not trustworthy $\left(d i_{A} / d \sigma_{i A}{ }^{2}>0\right)$. Conversely, reliable information expresses the true economic distribution of the acquisition gains; no noise is added to it $\left(i_{A}=0, \sigma_{i A}{ }^{2}=0\right)$. The model of trustworthiness introduces a selflimitation to information manipulation; otherwise, the bias would be unlimited. Taking delivery by the buyer of noisy information entails two contradictory effects: positive bias results in the buyer paying more in cash, but at the same time, a balancing effect will limit that trend with a larger perceived risk (see last term of RHS in (6)). The buyer protects himself by increasing the number of shares to pay for the takeover to transfer some of the risk to the seller. Figure 2 shows how the optimal cash-payment percentage changes between $0 \%$ and $100 \%$ according to the initial relative size $A_{0} / S_{0}$ of the target compared to the acquirer and the size of the information bias.

\section{INSERT figure 2}

Testable propositions result from the previous developments for public offers issued by the acquiring firm.

Proposition 1 - In mixed-payment situations, takeovers of positively correlated target and initiator firms should offer a lower payment in shares. Conversely, a strategy for diversifying activities will correspond to buyers offering a higher proportion of cash.

Proposition 2 - For the acquirer, the cash-payment portion increases with expectations of acquisition gains and synergies.

-) Evidence of a relationship between the mix of payments and the sharing of gains The payment structure depends on the sharing of synergies and gains, $c_{b}$. The sign of the derivative $d k_{b} * / d c_{b}$ is always positive for values satisfying condition (C1) (see Annex 2). From the buyer's point of view, a trade-off develops. He wants to pay more in cash when the acquisition price increases a little. In the case of (slightly) higher expectations of profit, the buyer can pay a marginally higher transaction price and agree to give a larger part $c$ of the acquisition gain to the seller. However, by paying more in cash, he will share a lower part of the future gain of acquisition with new shareholders. 
An optimal contract design will involve the relationship between the sharing of the acquisition gain (in fact, the offer price) and the means of payment. In the final phase of the negotiation process, a revision of the cash-payment portion may involve an increase in the offer price (which means a higher $c$ ) e. What is most important is that in non-hostile situations, a relationship exists such that the offer price proposed by the buyer and presented as acceptable by both parties will be influenced by the payment scheme. This highlights the existence of a process that leads to an acceptable package, which covers the transaction price and the means of payment.

Proposition 3 - In non-hostile acquisitions, when the final transaction terms are negotiated, a trade-off develops from the buyer's perspective; an increase (decrease) in the bid price is linked with a higher (lower) proportion of cash payments.

The optimal sharing of the acquisition gain is also identified by deriving the certainty equivalent of the expected profit (see equation A1 in the Annex) in relation to $c_{b}$. We obtain a relationship similar to (6). From the buyer's point of view, there is an infinite number of optimal solutions to describe a curve in the two-dimensional plan $(k, c)$ because $\alpha$ is itself a function of $c$ :

$$
1-c_{b} *=\frac{\left(\varepsilon_{A}+\varepsilon_{S}+i_{A}\right)\left[1+\left(1-k_{b} *\right) \alpha\left(c_{b} *, .\right)\right]}{\mu\left(\sigma_{A, b}^{2}+\sigma_{S}^{2}+2 \rho \sigma_{A, b} \sigma_{S}\right)}
$$

The more important the future profit is, the more the buyer will want to retain a large part of it. In particular, we observe that it is not optimal for the buyer to retain all of the acquisition gain $\left(c_{b}{ }^{*}=0\right)$, which might have appeared as an intuitive optimal solution for him. The buyer has an interest in sharing the gain, which increases the seller's exposure to risk through a payment with shares and, consequently, limits the buyer's own exposure to risk.

\subsection{Situation of the target's shareholders}

The sellers anticipate an additional profit resulting from a share payment. Their certain profit is in cash part of the transaction price $A_{D}$. However, compared to a pure payment in cash, they receive a part of the wealth of the acquiring firm after merging. They should take into account not only the dilution but also the potential profits or losses on the issued shares received for payment. These new shares are bought on the basis of a value (1-k) $\alpha S_{0}$ (see Equation (1)). The value of their share of capital held after merging is equal to their percentage 
of capital, $(1-k) \alpha[1+(1-k) \alpha]$, multiplied by the value of the merged firm after acquisition, $\left(S_{0}+A_{0}+\varepsilon_{A}+\varepsilon_{S}-k A_{D}\right)$.

When the target's shareholders sell their firm, the value of which is $A_{0}$ before takeover, they receive shares and cash on the basis of a transaction price that includes a part of the potential acquisition gains. In a mixed-payment scheme, their net profit is partly captured in the transaction price and partly linked to capital gains or losses, as observed in the following equation:

$\tilde{\pi}_{s}=k A_{D}+\frac{(1-k) \alpha\left(S_{0}+A_{0}+\widetilde{\varepsilon}_{A}+\widetilde{\varepsilon}_{S}-k \cdot A_{D}\right)}{1+(1-k) \alpha}-A_{0}=\frac{(1-k) \alpha\left(1-c_{s}\right)\left(\widetilde{\varepsilon}_{A}+\widetilde{\varepsilon}_{S}\right)}{1+(1-k) \alpha}+c_{s}\left(\widetilde{\varepsilon}_{A}+\widetilde{\varepsilon}_{S}\right)$

The optimal mix of payment for the seller is (see Annex 3)

$$
k_{S}^{*}=1+\frac{\left(\varepsilon_{A}+\varepsilon_{S}+i_{S}\right)-c_{S} \mu\left(\sigma_{A}^{2}+\sigma_{S}^{2}+\sigma_{i S}^{2}+2 \rho \sigma_{A}\left(\sigma_{S}^{2}+\sigma_{i S}^{2}\right)^{1 / 2}\right)}{\alpha\left(\varepsilon_{A}+\varepsilon_{S}+i_{S}-\mu\left(\sigma_{A}^{2}+\sigma_{S}^{2}+\sigma_{i S}^{2}+2 \rho \sigma_{A}\left(\sigma_{S}^{2}+\sigma_{i S}^{2}\right)^{1 / 2}\right)\right)}
$$

Figure 3 illustrates the optimal means of payment for the seller according to the size of the information bias he is exposed to regarding the buyer's value.

\section{INSERT figure 3}

A partial payment with shares only appears if $k_{s} *<1$, which implies the following:

$$
\left(\mu\left(\sigma_{A}^{2}+\sigma_{S, b}^{2}+2 \rho \sigma_{A} \sigma_{S, b}\right) c_{S}\right)<\left(\varepsilon_{A}+\varepsilon_{S}+i_{S}\right)<\left(\mu\left(\sigma_{A}^{2}+\sigma_{S, b}^{2}+2 \rho \sigma_{A} \sigma_{S, b}\right)\right)
$$

If this condition is not satisfied, the seller is not interested in receiving shares but rather only cash. It also means that the sellers will only accept a mixed payment scheme if the expected profit lies within a given range. A mixed cash-share payment is justified between the two limits identified in condition (C2). From (10), we obtain the derivative versus $c_{s}$ of the optimal cash payment for the seller. At optimum payment, for the case in which perspectives of gain relative to risk satisfy the condition for mixed payment schemes (i.e., C2), the derivative $d k_{s} * / d c_{s}$ is always positive. The seller will accept a trade-off between a higher share payment and a slightly lower transaction price; he will look for a higher proportion of the future expected acquisition gain through shareholding (see Annex 4).

In conclusion, assuming both conditions $\mathrm{C} 1$ and $\mathrm{C} 2$ are satisfied, the buyer and seller are both in a position to negotiate. This paves the way for a trade-off between the equilibrium 
acquisition price and the mix of payments. In a static context with exogenous parameters, a joint optimum agreement is possible. However, we need to consider that some variables are endogenous in the negotiation process.

\section{$\underline{3 \text { - Information policy and the negotiation process }}$}

The communication/manipulation policy is crucial in the negotiation process. The derivative of $k_{b}$ with regard to the information bias from the seller is always positive. We also observe that $d k_{b} * / \sigma_{i A}$ is negative, which means that poor information quality (i.e., trustworthiness) regarding the expectations of economic gain attached to the target firm will entail a protective behavior on the part of the buyer who wants to pay less in cash. The information bias coming from the seller modifies the equilibrium locus of the optimal solutions for the buyer $\left(c^{*}, k^{*}\right)$. A positive bias moves the buyer's equilibrium curves downward. Consequently, the crossing point with the seller's curve moves toward higher values of the captured acquisition gain, $c$. The information and communication policy of the seller aims to issue an optimistic bias to move the transaction price higher and, more precisely, to increase the captured part of the total acquisition, which incidentally may entail being paid less in cash (see Figure 4).

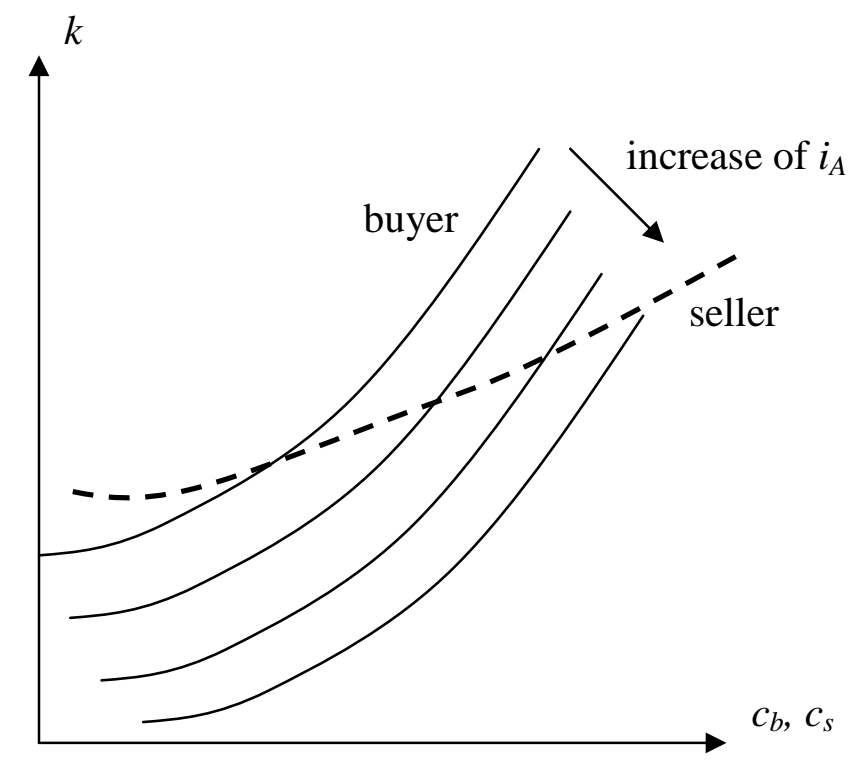

Figure 4: Situation of the buyer with information asymmetry

The information bias of the seller may eventually be negative. This means that the target's shareholders may have advantages in delivering prudent information on the future profit of the firm to receive an optimal payment corresponding to their view of the economic prospects of 
the merged firm. The elements leading to an optimistic bias by the buyer are the following: expected economic losses at the buyer's level, low synergies, high target economic risk and negative correlation. Conversely, a negative information bias may occur with expected economic gains, low economic risk and strong correlation between activities. Note that the forecast of significant gains will limit the seller's incentive to manipulate information; conversely, losses may favor optimistic biases.

If we want to design the conditions for a joint equilibrium for the buyer and the seller, we should obtain $k^{*}{ }_{b}=k^{*}$, at least for admissible limits to $k^{*}$ (i.e., $k<1$ ), which means that conditions (C1) and (C2) are both verified. The definition of a joint equilibrium involves a common solution for the two equations (6) and (10), each describing a curve in the $(c, k)$ plan. Nothing will ensure that the solution $k_{s}^{*}=k_{b}{ }^{*}$ will be acceptable, i.e., that $k$ will remain between 0 and 1 . If we had restricted the setup to a case of information symmetry, where both parties share the same information on the value of the target and the synergy gains of the acquirer (i.e., $i_{A}=i_{S}=0$ ), a joint optimal payment scheme would still be possible. An obvious solution appears for $c=1$, which means the total capture of the acquisition gain by the seller. ${ }^{9}$ In that situation, a joint equilibrium does not give any advantage to the buyer, who will not launch a takeover. We find here Grossman and Hart's (1980) well-known conclusion. To restore the economic interest of a takeover and the possibility of an agreement including mixed payment schemes, we have to consider information asymmetries.

In the two-dimensional plan $(c, k)$, the two optimal curves of the seller and buyer have different slopes. The terms of the trade-offs between the transaction price and the percentage paid in cash are not the same from each party's point of view (see Annex 4). They cross, at most, once in the feasible contact set ( $k$ and $c$ below 100\%). More precisely, Equations (6) and (10) define two families of curves depending on, respectively, $i_{A}$ and $i_{S}$. At equilibrium, a three-equation set with three variables may determine the values of $k^{*}, c_{b}$ and $c_{s}$ (Equations (3), (6) and (10)). ${ }^{10}$ The solution does not depend on the relative size of the two firms but rather directly on the biases $i_{A}$ and $i_{S}$ and on the information uncertainty linked to them. The existence of biases makes it easier to satisfy the two conditions (C1) and (C2). Consequently, it retroactively shows how the agreement on the mix of payments influences the sharing of the synergy gains and the final setting of the acquisition price. It means that the process is whole and that, implicitly, the two aspects of the deal should be determined jointly. Obviously, we have developed a stylized negotiation process based on an ex ante forecast of uncertain variables or ex ante transaction 
terms. Only ex post transaction data publicly proposed in takeover bids or officially settled between parties are empirically observable.

The negotiation process may develop in two different and extreme contexts: the context of a fixed transaction price or of pure bargaining. In a once-fixed transaction-price context, the first step (a) is the result of a bid by the buyer, who begins with a given information set (see the timeline in Figure 5). Information asymmetry is fixed by the initial values of the informational context $\left[i_{A}, i_{S}\right]$ and is linked to $\sigma_{i A}$ and $\sigma_{i S}$. In a second step (b), both parties agree on the transaction price and the ratio of exchange between the two firms (for instance, through the acceptance of a takeover bid). Then (c), both parties should negotiate the payment mix. In that context, the transaction price is exogenous and given. Observing Figure 5, the initial transaction price corresponds to a given value for the captured acquisition gain $c_{0}$. The initial intersection corresponding to a joint contract between the two parties is not in line with the agreed-upon transaction price. At step (d), because $d k / d c$ is non-null, both parties will revise the captured part of the acquisition gain using a communication policy. According to Equation (3), the information bias issued by one party is changed to modify the value of the captured acquisition gain, as perceived by the other party (see Footnote 11). Then (step (e)), the seller will move the buyer's equilibrium contract curve upward to set the agreement on the payment mix in line with the transaction price. To do so, he will modify the information bias that he projects about the future profitability of the target firm. To move the buyer's curve upward in Figure 4, he should reduce the information bias. Therefore, agreement is achieved by delivering some private information and reducing information asymmetry.

\begin{tabular}{|c|c|c|c|c|}
\hline (a) & (b) & (c) & (d) & (e) \\
\hline $\begin{array}{l}\text { Initial } \\
\text { information } \\
\text { set }\end{array}$ & $\begin{array}{l}\text { Agreement } \\
\text { on the } \\
\text { transaction } \\
\text { price }\end{array}$ & $\begin{array}{l}\text { Negotiation } \\
\text { of the } \\
\text { payment } \\
\text { mix with an }\end{array}$ & $\begin{array}{l}\text { Joint } \\
\text { modification } \\
\text { of } \\
\text { information }\end{array}$ & $\begin{array}{l}\text { Convergence } \\
\text { of contract } \\
\text { curves in line } \\
\text { with the }\end{array}$ \\
\hline & & $\begin{array}{l}\text { exogenous } \\
\text { transaction } \\
\text { price }\end{array}$ & biases & $\begin{array}{l}\text { fixed } \\
\text { transaction } \\
\text { price }\end{array}$ \\
\hline
\end{tabular}

Figure 5: Timeline of the negotiation process in the context of a fixed transaction price 
Observing Figure 6, we can imagine that the seller's curve may also decrease to achieve the agreement. This is more difficult because it would imply an increase in the information bias $i_{S}$, i.e., more manipulation. However, a self-limiting mechanism of trustworthiness will develop. ${ }^{11}$ Exaggeration in forecasting entails a decrease in the quality of the perceived future acquisition gain and, ultimately, non-convergence between the parties. A balancing effect will make the negotiation process lead to an agreement with the partial delivery of private information and a reduction of information asymmetry between the parties. If the initial captured acquisition gain is located on the right side of the initial contract intersection, a similar convergence mechanism will occur to reduce $i_{S}$ based on the disclosure of private information by the buyer. In the context of a fixed transaction price, the convergence will be based on an improvement of the quality of information and a reduction of information asymmetry.

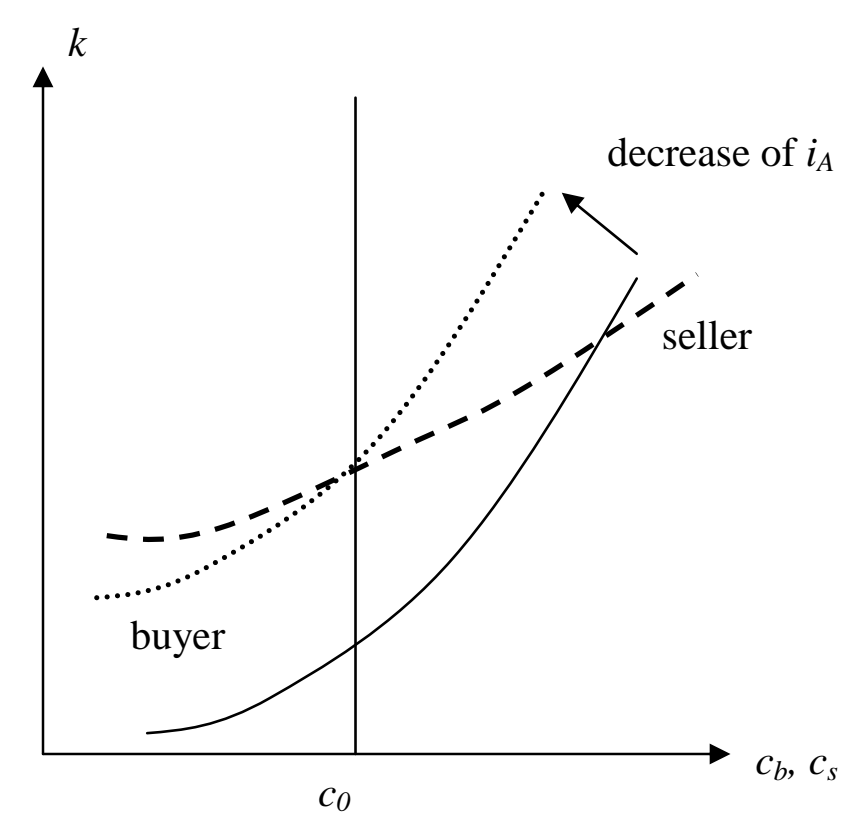

Figure 6 Context of the exogenous transaction price

In the context of pure bargaining, the buyer and seller will begin with asymmetric information sets (step (a) in Figure 7). The two initial contract curves of the buyer and seller cross. At step (b), the buyer begins by proposing a contract located on his optimal curve. This contract is not optimal to the seller. The negotiation process develops jointly by setting the transaction price (indirectly, $c$ ) and the payment mix (i.e., $k$ ). Many tools can be used to bargain (step (c)). Modification of the information biases will influence the calculation of the other party and the location of that party's optimum contract curve. Decreasing trustworthiness, when the expected future acquisition gains of the target or the acquirer are heavily manipulated, triggers a self- 
balancing effect and favors the improvement of information quality. However, the parties can do without communicating information on future profits; they can directly play off the terms of the transaction. For instance, the buyer can propose a higher acquisition price and, at the same time, increase the cash-payment portion. The symmetric trade-off reasoning between the transaction price and the payment mix will favor convergence (step (d)).

(a)

Initial

information set and initial setting

of the contract (b) (c)

First proposition

Barga information and/or proposition of new transaction terms (d)

Convergence

of contract

curves curves

Figure 7: Timeline of the pure bargaining context

In the context of pure bargaining, the transaction price is endogenously and jointly set along with the payment mix. Modification of the initial asymmetric information set is not needed for the parties to converge. Particularly, it is not necessary that the two parties agree to share identical information sets. Between the pure bargaining context and the fixed exogenous transaction-price context, many mixed situations may occur. What should be noticed is that the results of the negotiation process differ according to the negotiation context. The analyses of the transaction package differ from each side, but the information symmetries after the negotiation also may or may not have changed. The negotiation process is an opportunity for the acquirer, by paying a slightly higher price and/or by paying a bit more in cash, to learn more about the target firm.

The two polar contexts that are referred to can have institutional correspondences with real negotiation modes in M\&As. For instance, takeover bids using public offers will make the buyer state the transaction price. The toughest situation is the pure and blind "take-it-or-leaveit" offer. Because the terms of payment are publicly set, no formal negotiation process develops. However, the setting of the terms before the public phase is conducted with an investment bank that will help design the considerations according to the initiator's goals. The offer price is based on the former's knowledge of the market. The investment bank may also contact some institutional investors holding stakes of capital to gauge their reaction. Because of reputational concerns (i.e., bank league tables), they are interested in the success of the 
transaction. With a public auction, the initiator can also modify the terms of his offer according to the market reaction, or another acquirer may use this information to compete and establish a more attractive offer. A pure bargaining context develops into a non-hostile acquisition, either private or public. The managers of the two sides will negotiate the terms of the takeover, which is then publicly announced. The target's board may reject, accept or recommend the offer. The structure and context of the negotiation process between parties play a central role in determining optimal contracts. Creating room for bargaining and negotiation is essential because it allows for a reduction in information asymmetry and helps to reach a final agreement, even when facing an adverse selection problem, when each party has private information. Officer (2003) developed a similar analysis of the influence of termination fees in acquisitions, which encourages the delivery of private information in the bidding process.

The information biases are endogenous in the negotiation process. To explain convergence in the adjustment process, we may consider the cost associated with a possible decrease in trustworthiness. The higher the forecasted and announced future values of both firms are, the more they entail biased information and the more it becomes doubtful and noisy for the party who knows he is less informed. Mathematically, we can hypothesize a positive relationship, i.e., a larger $\sigma_{i}^{2}$ with a larger information bias $i$. An incentive to disclose better quality information develops. A lower bias and a lower perceived risk by the less-informed party move his trade-off contract curve. A change in the information set in the negotiation process is generally linked to better quality, reliable forecast of the future gains disclosed to the other party, which can occur in the negotiation process of a non-hostile takeover before the terms of the takeover are made public. The same can also occur when the bidder revises the payment structure, and can also occur implicitly without a formal negotiation process. If a buyer modifies the terms of payment with a lower proportion in cash, a trend of exaggeration regarding the future synergy and acquisition gains is revealed. This analysis leads to testing the hypothesis of an increasing flow of information linked to the modification of the mix of payment during the takeover negotiations. An active communication policy with new perspectives, business plans or public notices is a means to facilitate convergence between sellers and buyers concerning the conditions of the takeover, particularly the means of payment.

The previous developments must be mitigated with the existence of self-regulation in these information policies from both sides. Rational economic agents are aware that they are exposed to information asymmetries and forecast the risk due to information bias. Any piece of 
information is weighed by a specific uncertainty due to its issuer's behavior, which accumulates with the economic uncertainty of the future expected gains. That information noise is analyzed in terms of trustworthiness for the one who receives information. We should take into account that trustworthiness is endogenous and depends on the level of economic gains announced by one party. A rational equilibrium exists in the sense that exaggeration makes information poorly credible. The buyer, who receives information, perceives information risk similarly to economic risk. He attempts to globally cover himself against that risk. One possibility, as highlighted above, is to make the seller an associate with a largely share-based payment, which will expose him to losses coming from his own exaggerated information. However, reciprocal mechanisms of self-regulation may limit the behavior of the buyer. Market efficiency, disclosure rules and the existence of powerful regulatory authorities will force a listed acquirer to deliver trustworthy forecasts of future gains. The pressure of independent financial analysts, if we assume they effectively play their role of expertise, can lead to the delivery of uncertain but unbiased forecasts on the future gains resulting from a takeover. Such a situation may be a general improvement for investors, particularly for the target's shareholders, but, paradoxically, the acquiring firm appears to be informationally dominated vis-à-vis a target firm that is not listed. Capital gains of the targets are then easier to dissimulate, and strategies of exaggeration become possible.

The previous analysis leads to some propositions that can be tested empirically:

- Proposition 4 - The modification of the payment structure during the process of a takeover accompanies a decrease of information asymmetry and an improvement in the forecast of the profitability resulting from the acquisition.

- Proposition 5 - The information flow comes from the party that revises the payment scheme and/or the price; practically, in formal procedures, it comes from the acquirer.

\section{Conclusion}

During takeover offers, a mixed payment weighing cash and shares explains itself without referring to a pure strategic game aimed at discouraging competitors. The design of an optimal mixed-payment scheme expresses the risk aversion of the buyer and seller, who both face a double risk. If the buyer questions the economic value of the acquired assets, then the seller, who is partly paid with shares, likewise questions the future gains of synergy. The setting of an 
optimal weighing of the means of payment appears as a solution to the problem. Paying with newly issued shares allows the buyer to insure himself against information risk and uncertainty about the real economic value of the target's assets. However, at the same time, issuing shares will dilute the holdings of the acquirer's current shareholders. The seller also suffers from information asymmetry and can be given biased perspectives about the future of the acquisition. The means of payment, particularly mixed payments, act as a partial insurance mechanism in an acquisition transaction. The possibility to design risk sharing through share payment is as efficient as other contract provisions. Asset or liability guarantees in a formal contract that agreement can play the same role but suffers from the fact that, by definition, a contract is ex ante incomplete. The payment mix allows the sharing of residual risks and links economic uncertainty to informational risk. Expectations of acquisition gains above a minimum threshold level will lead to a full-cash payment by the buyer. A mixed payment scheme indicates a balance between insurance and ex ante prospects for profit. This explains why, in the market, mixed payments and pure cash offers may coexist.

A takeover is a contract, and a successful agreement is one in which the seller's optimal preferences of payment have been taken into account. The convergence to an agreed-upon payment scheme means that a process of information exchange occurred successfully in the sense that the noisy future acquisition gains that are reciprocally communicated to the other party in the negotiation process between the buyer and the seller finally are compatible. It does not mean that there exists equally and symmetrically shared information, rather only limited biases. Exaggeration biases exist and are part of the policy of communication from one party to the other. A self-regulation mechanism of trustworthiness will limit information risk for the party receiving the information. Limitless biases will lead to systematically extreme solutions of pure cash or pure share payments. If bias and exaggeration increase the fuzziness of information linked to future economic value, the buyer (seller) will try to cover that risk and will propose a payment with more shares (cash). The communication policy seems to gain greater importance during negotiation of the means of payment or when the terms of payment are publicly revised in a mixed takeover offer. It also appears that the final takeover price should be sensitive to the design of the payment scheme. A cash-equity payment mix conveys information and manages information risk; its setting has value and will marginally modify the transaction price offer. The aforementioned findings offer possibilities for empirically testable propositions. 


\section{Annex 1}

The certainty equivalent (EC) is obtained assuming an exponential utility function with risk aversion $\mu$. The buyer's EC after dilution is

$$
E C_{b}=\frac{\left(1-c_{b}\right)\left(\varepsilon_{A}+\varepsilon_{S}+i_{A}\right)}{[1+(1-k) \alpha]}-\frac{1}{2} \mu \frac{\left(1-c_{b}\right)^{2}}{[1+(1-k) \alpha]^{2}}\left(\sigma_{A, b}^{2}+\sigma_{S}^{2}+2 \rho \sigma_{A, b} \sigma_{S}\right)
$$

To design the optimal payment in cash, we derive (A1) in relation to $k$. At optimum, equalizing to zero, the buyer's optimal payment scheme is

$$
k_{b}^{*}=1+\frac{1}{\alpha}-\frac{\left(1-c_{b}\right) \mu\left(\sigma_{A, b}^{2}+\sigma_{S}^{2}+2 \rho \sigma_{A, b} \sigma_{S}\right)}{\alpha .\left(\varepsilon_{A}+\varepsilon_{S}+i_{A}\right)}
$$

Replacing $\alpha$ makes explicit the relative size effect of the two firms $S_{0} / A_{0}$ and gives Equation (5), as shown in the text.

\section{Annex 2}

We obtain the derivative $d k_{b} * / d c_{b}$ from (6) by combining different terms. The transaction exchange ratio $\alpha$ depends on $c_{b}$, with $d \alpha / d c_{b}>0$.

$$
\begin{aligned}
\frac{d k_{b} *}{d c_{b}}= & -\frac{\left(d \alpha / d c_{b}\right)}{\alpha^{2}}+\frac{\mu \cdot\left(\sigma_{A}^{2}+\sigma_{S}^{2}+\sigma_{i A}^{2}+2 \rho \sigma_{A} \sigma_{S}\right)}{\alpha \cdot\left(\varepsilon_{A}+\varepsilon_{S}+i_{A}\right)} \\
& +\frac{\left(d \alpha / d c_{b}\right)(1-c) \mu\left(\sigma_{A}^{2}+\sigma_{S}^{2}+\sigma_{i A}^{2}+2 \rho \sigma_{A} \sigma_{S}\right)}{\alpha^{2} \cdot\left(\varepsilon_{A}+\varepsilon_{S}+i_{A}\right)}
\end{aligned}
$$

Considering the global gain as perceived by the acquirer $\varepsilon_{b}=\left(\varepsilon_{A}+\varepsilon_{B}+i_{A}\right)$ and the whole risk $\sigma_{b}^{2}=\left(\sigma_{A, b}^{2}+\sigma_{S}^{2}+2 \rho \sigma_{A, b} \sigma_{S}\right)$, after manipulation, we observe that the sign of the derivative follows a second-degree form:

$$
\frac{d k_{b} *}{d c_{b}}=\operatorname{sgn}\left[-\left(\varepsilon_{b}\right)^{2}+\mu \sigma_{b}^{2} \varepsilon_{b}+A_{0} \mu \sigma_{b}^{2}\right]
$$

A non-zero derivative means that the choice of a payment scheme will influence the previously negotiated transaction price. The sign of the derivative $d k_{b} * / d c_{b}$ does not depend on $c_{b}$. It is always positive for values satisfying condition (C1). The sign of $d k_{b} * / d c$ increases for values of the expected acquisition gain below $\mu \cdot \sigma_{b}^{2} / 2$ and decreases for values above.

\section{Annex 3}

We calculate the equivalent certainty for a risk-averse seller: 


$$
\begin{aligned}
& E C_{s}=\left(\frac{\left(1-k_{s}\right) \alpha\left(1-c_{s}\right)\left(\varepsilon_{A}+\varepsilon_{S}+i_{S}\right)}{1+\left(1-k_{s}\right) \cdot \alpha}+c_{s}\left(\varepsilon_{A}+\varepsilon_{S}+i_{S}\right)\right) \\
& -\frac{1}{2} \mu\left(\frac{\left(1-k_{s}\right) \alpha\left(1-c_{s}\right)}{1+\left(1-k_{s}\right) \cdot \alpha}+c_{s}\right)^{2}\left(\sigma_{A}^{2}+\sigma_{S, s}^{2}+2 \cdot \rho \sigma_{A} \sigma_{S, s}\right)
\end{aligned}
$$

The seller is exposed to an uncertain value of the shares he will receive as payment. To reach the optimal payment structure, we set the derivative of the expected wealth of the buyer given in Equation (A5) in relation to $k_{s}$ to zero. Independence between information noise from the buyer $i_{S}$ and his synergy profit $\varepsilon_{S}\left(\operatorname{soc} \operatorname{cov}\left(i_{S}, \varepsilon_{S}\right)=0\right)$ is assumed. Thus, we obtain Equation (10).

\section{Annex 4}

The transaction exchange ratio $\alpha$ depends on $c_{s}$. From (10), the derivative versus $c_{s}$ of the optimal cash payment for the seller has the same sign as the following:

$$
\frac{d k_{s} *}{d c_{s}}=\operatorname{sgn}\left[\begin{array}{c}
\frac{-\mu\left(\sigma_{A}^{2}+\sigma_{S}^{2}+\sigma_{i S}^{2}+2 \rho \sigma_{A}\left(\sigma_{S}^{2}+\sigma_{i S}^{2}\right)^{1 / 2}\right)}{\alpha\left(\varepsilon_{A}+\varepsilon_{S}+i_{S}-\mu .\left(\sigma_{A}^{2}+\sigma_{S}^{2}+\sigma_{i S}^{2}+2 \rho \sigma_{A}\left(\sigma_{S}^{2}+\sigma_{i S}^{2}\right)^{1 / 2}\right)\right)} \\
-\frac{\left(d \alpha / d c_{s}\right)\left(\varepsilon_{A}+\varepsilon_{S}+i_{S}-c_{S} \mu\left(\sigma_{A}^{2}+\sigma_{S}^{2}+\sigma_{i S}^{2}+2 \rho \sigma_{A}\left(\sigma_{S}^{2}+\sigma_{i S}^{2}\right)^{1 / 2}\right)\right.}{\alpha^{2}\left(\varepsilon_{A}+\varepsilon_{S}+i_{S}-\mu \cdot\left(\sigma_{A}^{2}+\sigma_{S}^{2}+\sigma_{i S}^{2}+2 \rho \sigma_{A}\left(\sigma_{S}^{2}+\sigma_{i S}^{2}\right)^{1 / 2}\right)\right)}
\end{array}\right]
$$

Considering the global gain as perceived by the seller $\varepsilon_{s}=\left(\varepsilon_{A}+\varepsilon_{B}+i_{S}\right)$ and the whole risk $\sigma_{s}^{2}=\left(\sigma_{A}^{2}+\sigma_{B, s}^{2}+2 \rho \sigma_{A} \sigma_{B, s}\right)$, after manipulation, the sign of the derivative follows a seconddegree form:

$$
\frac{d k_{s} *}{d c_{s}}=\operatorname{sgn}\left[\left(\varepsilon_{s}\right)^{2}+A_{0} \mu \sigma_{s}^{2}\right]
$$

We observe that $k$ and $c$ interact from the seller's point of view because the partial derivative is not null. The derivative $d k_{s} * / d c_{s}$ is always positive and shows a trade-off. We notice that the derivatives (A4) and (A7) are different and that the trade-offs have different slopes for the buyer and the seller. 


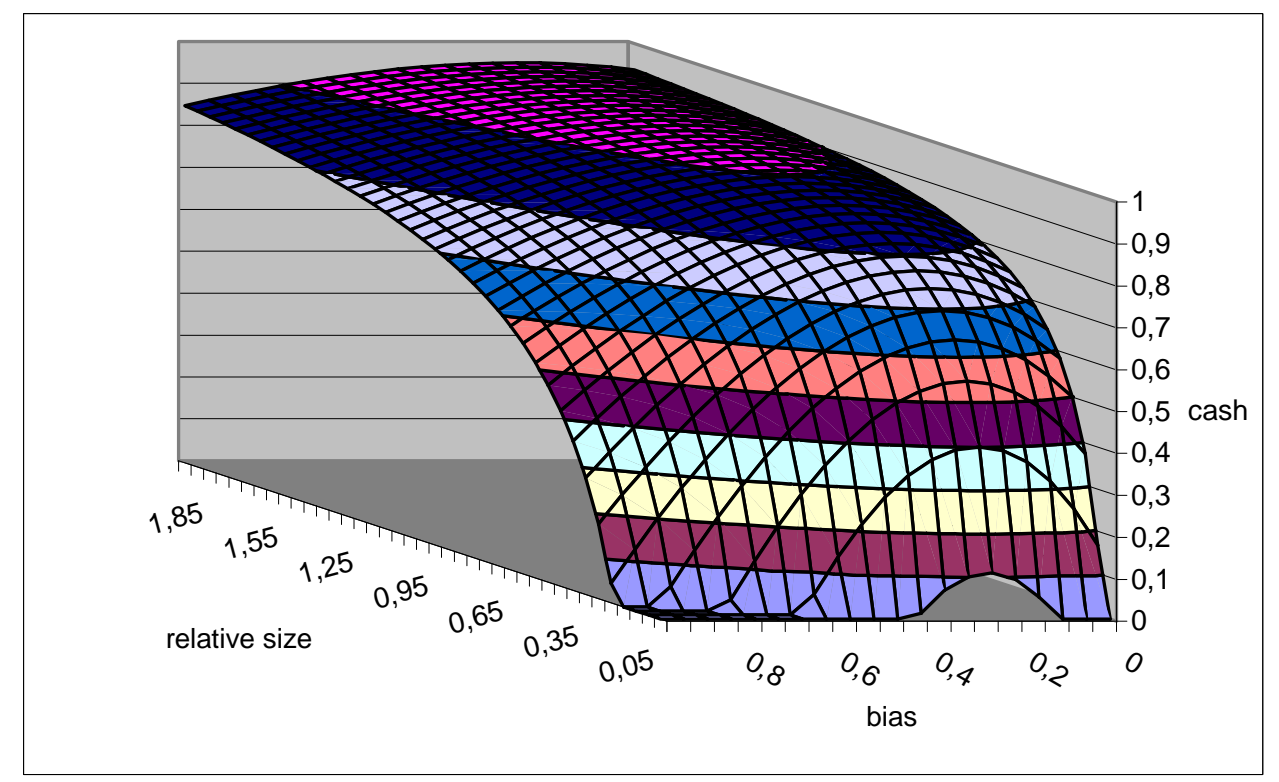

Figure 2: Optimal cash payment for the buyer according to the positive exaggeration bias issued by the seller

(relative size: the ratio of the initial target asset size compared to the acquiring firm size, $A_{0} / S_{0}$, which varies from $5 \%$ to $200 \%$ of the acquirer's initial value, $S_{0}$; bias: the size of the exaggeration bias in the target's assets value, which varies from $0 \%$ to $100 \%$ of the average true economic acquisition gain $\varepsilon_{\mathrm{A}}$; the parameter values in the equation, information bias $i_{A}$ follows a binomial distribution of parameter $p, S_{0}=10, \rho=0.5, \mu=4, \varepsilon_{A}=\varepsilon_{S}=1, \sigma_{A}=\sigma_{S}=1, c=0.25, p=0.5$ )

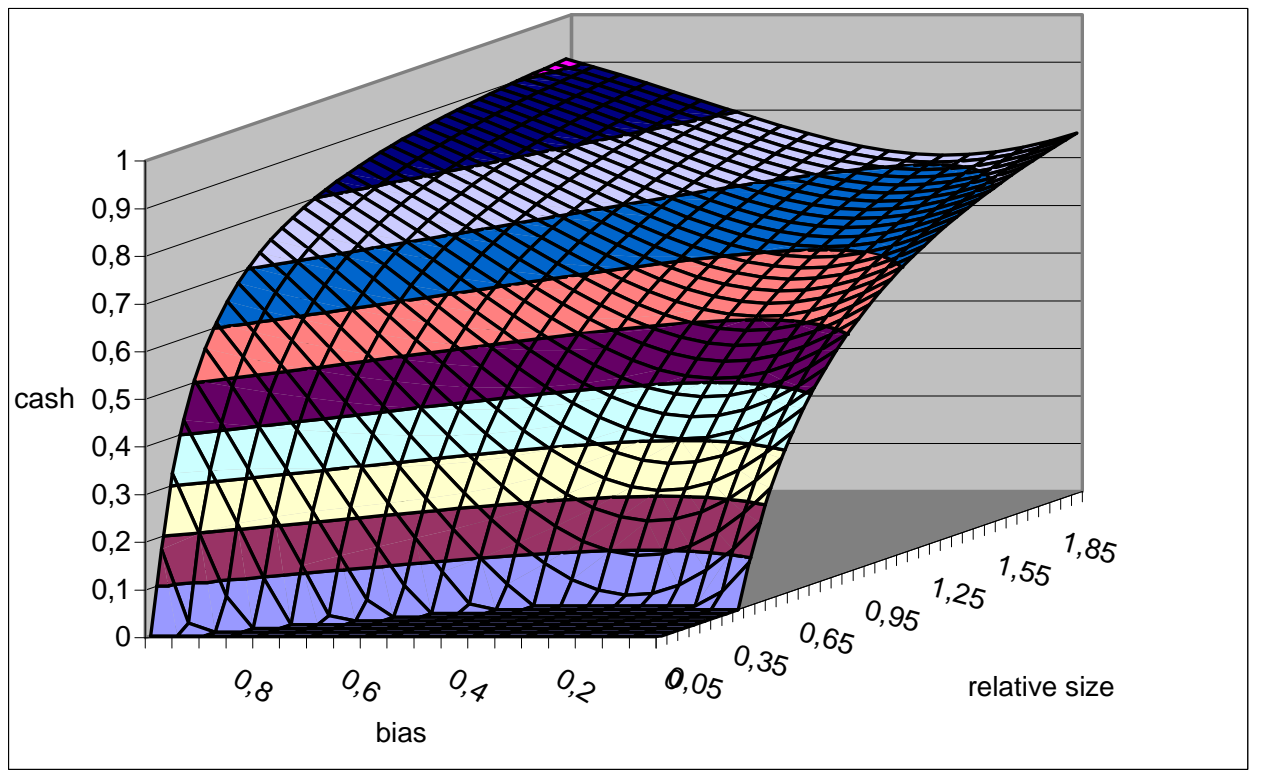

Figure 3: Optimal cash payment for the seller according to positive exaggeration bias issued by the buyer

(see the legend, Figure 1; bias: the size of the exaggeration bias on the acquisition/synergy gains in the acquirer's assets, which varies from $5 \%$ to $100 \%$ of the average true economic acquisition gain $\varepsilon_{S}$; binomial information bias: $S_{0}=10, \rho=0,5, \mu=4, \varepsilon_{A}=\varepsilon_{S}=1, \sigma_{A}=\sigma_{S}=0.5, c=0.25$, $p=0.5)$ 


\section{References}

Amihud Y., Lev B., \& Travlos N. (1990). Corporate control and the choice of investment financing: the case of corporate acquisitions. Journal of Finance, 45, ${ }^{\circ} 2$, 603-616.

André P., Kooli M.,. \& L'Her J.F. (2004). The long-run performance of mergers and acquisitions: Evidence from the Canadian stock market. Financial Management, 33, 27-43.

Antoniou A., \& Zhao H. (2004). Long-run post takeover stock return: The impact of overlapping return, takeover premium, and method of payment, EFMA Basel meeting, www.ssrn.com.

Bebchuk, L. A, (1994). Efficient and Inefficient Sales of Corporate Control, Quarterly Journal of Economics, 109, 957-993.

Bellamy D., \& Lewin W. (1992). Corporate takeovers, method of payment, and bidding firms' shareholder returns: Australian evidence, Asia Pacific Journal of Management, 9, $\mathrm{n}^{\circ}$ 2, 137149.

Ben-Amar W., \& André P. (2007). Large shareholder and form of payment in M\&A: Evidence from Canada, working paper, EFMA Symposium on Corporate governance, Milan

Berkovitch E., \& Narayanan M. (1990). Competition and the medium of exchange in takeovers, Review of Financial Studies, 3, 153-174.

Chang S., (1998). Takeovers of privately held targets, method of payment and bidder returns, Journal of Finance, 53, 773-784.

Chang S., \& Mais E. (2000). Managerial motives and merge financing, The Financial Review, 35, 139-152.

Cheng P., Li J., \& Tong W. (2008) Information Asymmetry in the Takeover Market, EFMA meeting, working paper, www.ssrn.com

Chevalier A., \& Redor E. (2007). Les théories expliquant le choix de la méthode de paiement dans le cadre d'une opération de fusion-acquisition, Banques et Marchés, mai-juin, n88, 46-54. Chevalier A., \& Redor E., (2010). The determinants of payment method choice in cross-border acquisistions, Bankers, Markets and Investors, juin, ${ }^{\circ} 106,4-14$

Cornu P., \& Isakov D. (2000). The deterring role of the medium of payment in takeover contest : theory and evidence from the UK, European Financial Management, 6, 423-440.

Da Silva Rosa R., Limmack R., \& Woodliff D. (2003) The equity wealth effect of method of payment in takeover bids for privately held firms, working paper, EFMA meeting Helsinki, www.ssrn.com

Eckbo E., Giammarino R., \& Heinkel R. (1990) Asymmetric information and the medium of exchange in takeovers; Theory and tests, Review of Financial Studies, 3, 651-675.

Faccio M., \& Masulis R. (2005) The choice of payment method in European mergers and acquisitions, Journal of Finance, 60, n³, 1345-1388.

Fishman M., (1989) Preemptive bidding and the role of the medium of exchange in acquisitions, Journal of Finance, 44, 41-571

Fuller K., Netter J., \& Stegemoller M. (2002) What do returns to acquiring firms tell us? Evidence from firms that make many acquisitions, Journal of Finance, 57, 1763-1793.

Goergen M., \& Renneboog L. (2004) Shareholder wealth effects of European domestic and cross-border takeover bids, European Financial Management, 10, 243-268.

Grossman S., \& Hart O. (1980) Takeover bids, the free-rider problem, and the theory of the corporation, Bell Journal of economics, 11, 42-64

Hansen R., (1987) A theory for the choice of exchange medium in mergers and acquisitions, Journal of Business, 60, 75-95. 
Heron R., Lie E. (2002) Operating performance and the method of payment in takeovers, Journal of Financial and Quantitative Analysis, 37, 137-155.

Houston J.F., \& Ryngaert M.D. (1997) Equity issuance and adverse selection: a direct test using conditional stock offers, Journal of Finance, 52, 197-219

Linn S.C., \& Switzer J.A. (2001) Are cash acquisitions associated with better post combination operating performance than stock acquisitions? Journal of Banking and Finance, 25, 11131138.

Loughran T., \& Vijh A. M. (1997) Do long-term shareholders benefit from corporate acquisitions? Journal of Finance, 52, $\mathrm{n}^{\circ}$ 5, 1765-1790.

Martin. K. J. (1996) The method of payment in corporate acquisitions, Investment Opportunities, and Management Ownership, Journal of Finance, 51, n ${ }^{\circ} 4,1227-1246$.

Martynova, M., \& Renneboog, L. (2006) Mergers and acquisitions in Europe: the fifth takeover wave. in: Renneboog, L. (Ed.), Advances in Corporate Finance and Asset Pricing, Elsevier,

Amsterdam, 15-75.

Martynova M., \& Renneboog L. (2009) What determines the financing decision in corporate takeovers: Cost of capital, agency problems, or the means of payment", Journal of Corporate Finance, 15, 290-315

Megginson W., \& Morgan A., \& Nail L. (2004) The determinant of positive long-term performance in strategic mergers: Corporate focus and cash, Journal of Banking and Finance, 28, 523-552.

Myers S., \& Majluf N. (1984) Corporate financing and investment decisions when firms have information that investors do not have, Journal of Financial Economics, 13, 187-221.

Officer M. (2003) Termination fees in mergers and acquisitions, Journal of Financial Economics, 69, 431-467.

Stulz R. (1988) Managerial control of voting rights: financing policies and the market for corporate control, Journal of Financial Economics, 20, 25-54.

Travlos N. (1987) Corporate takeover bids, method of payment and bidding firms' stock return, Journal of Finance, 42, 942-963.

Zhang L. (2009) Why do firms pay cash in acquisitions? Evidence from a demand perspective, AFA 2010 Atlanta Meetings Paper, available at SSRN: http://ssrn.com/abstract=1136343

\footnotetext{
${ }^{2}$ This theoretical assumption is coherent with the empirical analyses of Faccio and Masulis and of Martynova and Renneboog, who did not find any significant effect of the financial leverage of the initiator on the percentage of cash payments.

${ }^{3}$ They are considered a single shareholder and not a group of dispersed shareholders, which means that we implicitly assume that (i) their wealth is concentrated in the firm, and/or (ii) the risk linked to uncertain acquisition gains cannot be diversified in a portfolio. The first idea is in line with the characteristic of capital ownership in Europe and Asia, which is mainly concentrated. The second argument opens a debate about diversifiable risk. If the acquisition gains risk were diversifiable for small investors, the insurance motives would be second order in the acquisition transactions. Thus, we are led to conclude that cash payments should play a limited role in transaction settings, which is empirically counterfactual. We hypothesize that acquisition risk occurring in M\&A transactions is not diversifiable because these transactions are rare. Moreover, asymmetry of information finds its source in a risk linked to the manipulation of information, which is not diversifiable because it is generally a one-way exaggeration risk.

${ }^{4}$ This assumption is justified by the revolving role of investors who may be shareholders of a company, first acting as the acquirer and then as the target firm.

${ }^{5}$ Similarly, we have $\operatorname{cov}\left(\varepsilon_{A, b}, \varepsilon_{S}\right)=\operatorname{cov}\left(\varepsilon_{A}, \varepsilon_{S}\right)$ or, equivalently, $\operatorname{cov}\left(i_{A}, \varepsilon_{S}\right)=0$.

${ }^{6}$ A simplified model is possible with only one area of information asymmetry in favor of the seller if the acquiring firm is listed on a perfectly efficient market. In the case of an envisaged acquisition, the gains of acquisition and synergies are known in the market. Thus, the variable $\varepsilon_{S}$ is identified by the shareholders of the target. The only asymmetry benefit to the seller is that he can, for instance, hide some losses. The same argument of efficiency also
} 
applies to a listed target firm. In fact, the analysis here considers a bilateral negotiation process unknown to the market.

${ }^{7}$ Recall that $\alpha=A_{D} / S_{0}$, with $A_{D}$ defined by relation (3a).

${ }^{8}$ The local derivative of the cash payment with regard to the relative size is positive. However, it is calculated at the optimum point for a given profit. A small increase of the target size with the same absolute profit means a decrease in the expected profitability. Therefore, ceteris paribus, the buyer should react to the dilution of its profit by giving fewer shares to the target's shareholders and pay more in cash. This result cannot be extended because the derivative versus size should assume a constant profitability per invested dollar and a constant invested amount. When deriving with a constant diluting and financing amount $L=(1-k) . \alpha(k)$ (See Eq. 6), we obtain $\frac{d L}{d k^{*}}=(1-k) \cdot \frac{d \alpha}{d k^{*}}-\alpha$, with at optimum $\frac{d \alpha}{d k^{*}}>0$. The derivative is negative if $\alpha>-\left[1-\frac{(1-c) \mu \sigma}{\varepsilon}\right] \frac{1}{1-k}$.

If the condition $\mathrm{C} 1$ is satisfied, then a negative $d L / d k^{*}$ follows according the value for $\varepsilon$ (see Figure 1). This means that if the financial limit increases, the percentage of cash payments declines. In fact, cash payments are empirically lower with size. This is explained by the financial constraint argument, which is not considered in our basic mixed-payment model and gives theoretical support to full-share payments for larger deals. I thank a referee for this remark.

${ }^{9}$ This result comes from the hypothesis of identical risk aversions of the seller and the buyer. If we had considered different values for risk aversion, a joint equilibrium with a mixed payment could have also been set.

${ }^{10}$ The two equations ( $3 \mathrm{a}$ and $3 \mathrm{~b}$ ) are equivalent to $c_{b}\left(\varepsilon_{A}+\varepsilon_{S}+i_{A}\right)=c_{s} .\left(\varepsilon_{A}+\varepsilon_{S}+i_{S}\right)$ and assert that an agreement exists with a price sharing the net perceived value of the merger between the two parties.

${ }^{11}$ Here, we make the crucial assumption that more manipulation is bound by the self-limitation mechanism before the process of negotiation breaks. Thus, the initial assumption of success of the transaction (i.e., the existence of an agreement to sell and buy) is maintained. This point is important because without self-limitation, or with ineffective self-limitation, the exaggeration bias may be too much, the target will refuse to sell and the initial assumption of success of the transaction will no longer be satisfied, which internally questions our model. We thank a referee for this remark. 